\title{
Hackathon das Vertentes: competição de inovação em educação com desenvolvimento de artefatos computacionais
}

\author{
Carolaine Gabrielle dos Santos Barbosa ${ }^{1}$, Dárlinton Barbosa Feres Carvalho ${ }^{1}$, \\ Cláudio Eduardo de Souza ${ }^{1,2}$, Mayara Haddad Borges ${ }^{2}$, Celso Luiz de Souza ${ }^{3}$ \\ ${ }^{1}$ Universidade Federal de São João del-Rei - UFSJ \\ São João del-Rei/MG \\ ${ }^{2}$ Centro Universitário Tancredo Neves - UNIPTAN \\ São João del-Rei/MG \\ ${ }^{3}$ Instituto Federal de Educação, Ciência e Tecnologia do Sudeste de Minas Gerais \\ Campus São João del-Rei - São João del-Rei/MG \\ darlintoneacm.org
}

\begin{abstract}
In response to the emergency caused by the COVID-19 pandemic, a hackathon event was proposed to promote innovations in education through the development of computational artifacts. This article presents the proposed event, organized by a strategic alliance formed by the local innovation ecosystem, underlining its main results. It is worth mentioning the registration of 68 students from different cities in Brazil. Through the initial assessment, 36 participants were selected for a 5-day immersion journey. On the last day, seven projects were presented, being the best three awarded. Participants evaluated the event through questionnaires, granting it an NPS® Score of 76.
\end{abstract}

Resumo. Em resposta a emergência instaurada pela pandemia de COVID-19, foi proposto um evento do tipo hackathon buscando promover inovações na área de educação. Este artigo apresenta a proposta do evento, organizado por uma aliança estratégica formada pelo ecossistema de inovação da região, bem como os resultados obtidos. Destaca-se a inscrição de 68 estudantes de diversas cidades do Brasil, sendo 36 participantes selecionados para a jornada de imersão de 5 dias. No último dia houve a apresentação de 7 projetos, sendo premiados os 3 mais bem avaliados. $O$ evento foi avaliado pelos participantes com questionários, obtendo um NPS® Score de 76.

\section{Introdução}

O ano de 2020 foi marcado pelas dificuldades decorrentes da pandemia de COVID-19. O distanciamento social, dentre outras recomendações feitas pela Organização Mundial da Saúde (OMS), impactou diretamente nas formas de convívios pessoais. Todos os setores tiveram seus cotidianos ressignificados, como o comércio, o lazer, a tecnologia, a saúde, a segurança e a educação também [World Bank 2020].

O Ministério da Educação, através da portaria $n^{\circ} 343$, publicada no dia 17 de março de 2020, autorizou a substituição de aulas presenciais das instituições federais de 
ensino por aulas no formato de ensino à distância [Brasil 2020]. Dessa forma, foi necessário repensar os métodos de ensino oferecidos de forma a adaptar discentes e docentes, em um curto período de tempo, à nova realidade. As Tecnologias de Informação e Comunicação (TICs) digitais tiveram que ser amplamente adotas em todas as áreas para possibilitar a continuidade das atividades educacionais em meio à pandemia. Por meio de novas ferramentas tecnológicas em conjunto com novas práticas educacionais (ex: [Pimentel \& Carvalho 2020]), as aulas tiveram uma grande ruptura do modelo educacional.

Buscando contribuir neste cenário, o ecossistema local de empreendedorismo e inovação de São João del-Rei, contando com um papel protagonista de estudantes das instituições de ensino da região, propôs um evento no sentido de promover a sensibilização da comunidade local para o desenvolvimento de inovações digitais (i.e., artefatos computacionais) para apoiar na realização do ensino remoto. A proposta do evento foi do tipo hackathon, e o evento denominado Hackathon das Vertentes.

O termo hackathon é um neologismo criado a partir da junção de duas palavras, hack (não no sentido criminal) e maratona, visto que é uma competição intensa em que os participantes são desafiados coletivamente a resolver um problema por meio do desenvolvimento de novas tecnologias. Entre diversas iniciativas neste modelo, destacase o Hack for Brazil | Covid- 19, que foi uma iniciativa de hackathon online que teve como objetivo encontrar soluções para combater os impactos da Covid- 19 na sociedade. Este evento teve como tema investigar como a coordenação de esforços coletivos é realizada em contextos de grande escala e intenso dinamismo. O evento demonstra a capacidade que iniciativas como essa têm de promover a busca por novos questionamentos, bem como de manifestar o poder da ação coletiva [Verschoore, 2020].

Este artigo apresenta a proposta do Hackathon das Vertentes, detalhando sua realização, bem como os resultados obtidos. Considerando o caráter empírico na realização de um evento, foi empregada uma metodologia de trabalho conforme preconizado pelo Design Science Research. Os resultados obtidos corroboram as expectativas de que o evento hackathon, mesmo sendo uma edição virtual, contribui na capacitação dos participantes bem como promove a criação de inovações digitais.

O artigo está organizado como apresentado a seguir. A próxima seção apresenta a metodologia empregada na realização do trabalho apresentado neste artigo. A Seção 3 detalha o evento proposto, bem como relata sobre os resultados obtidos a partir da sua execução. Uma discussão promovendo uma reflexão sobre a realização do evento e seus resultados é apresentada Seção 4. Por fim, este artigo é concluído na Seção 5.

\section{Metodologia}

A fim de apresentar formalmente a metodologia utilizada no presente trabalho, utiliza-se o que esquema apresentado na Figura 1, que é baseado na proposta de Pimentel, Filippo e Santoro (2020). O detalhamento deste esquema é apresentado a seguir.

No diagrama que tem seus elementos principais destacados com diferentes cores e formatos, evidencia-se o Problema/Contexto (i.e. quadrado com bordas arredondadas em tons de vermelho), a etapa de Pesquisa em Projeto (i.e. em tons de verde com formato oval e a proposição de um artefato em um retângulo) com o desenvolvimento de artefato e a determinação de uma forma de avaliação (i.e. elementos relacionados à avaliação empírica são apresentados em caixas pontiagudas), e a etapa de Pesquisa em 
Ciência do Comportamento (i.e. em tons de azul com formato oval e a proposição de conjecturas teóricas em um retângulo), relacionada ao Ciclo do Rigor, em que as conjecturas devem ser verificadas empiricamente, apresentando novas evidências ao corpo de conhecimento.

O contexto desta pesquisa surge como consequência das adversidades decorrentes da pandemia de COVID-19. O problema em questão trata da demanda por inovações digitais para a educação devido às restrições impostas.

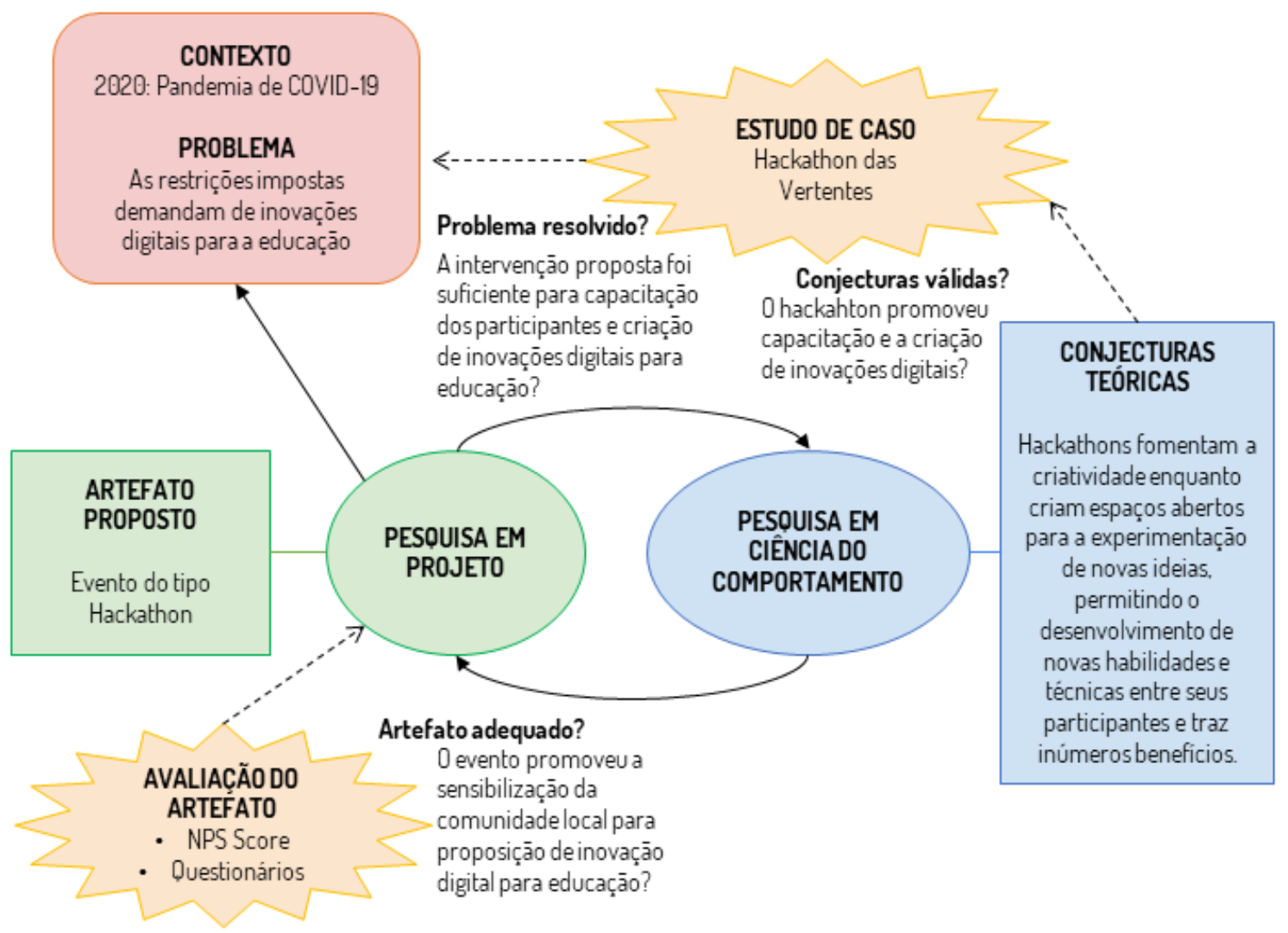

Figura 1. Esquema da metodologia utilizada neste trabalho

Em sequência, a etapa de pesquisa em projeto propõe um artefato incorporado à uma estratégia de avaliação. $\mathrm{O}$ artefato proposto é um evento do tipo hackathon para promover discussões na comunidade e elaborar uma solução digital inovadora que possibilite a continuidade das atividades letivas em meio à pandemia.

Com o propósito de verificar o impacto do evento proposto, foi incorporada uma avaliação por meio de questionários a partir de sua oferta à comunidade, em especial considerando a métrica de lealdade do cliente Net Promoter Score (NPS®). As evidências obtidas permitiram verificar na prática os impactos promovidos e que são reportados à comunidade acadêmica por meio deste artigo.

\section{Resultados}

O evento proposto nesta pesquisa foi uma jornada de imersão oferecida aos participantes a fim de apoiar o desenvolvimento de soluções inovadoras para resolver problemas ligados à educação de forma remota nos níveis fundamental e médio. 
A participação no evento foi restrita a estudantes dos ensinos médio, técnico e superior. Para alcançar este público, o evento foi divulgado através das redes sociais, por meio de compartilhamentos no WhatsApp, anúncios pagos realizados na plataforma do Instagram, bem como através de postagens feitas pelas organizadoras do evento. Deste modo, foram obtidas 68 inscrições. Para selecionar os participantes, foi solicitado o envio de um vídeo de até 2 minutos respondendo qual a motivação para se inscreverem no evento. Os 36 estudantes que enviaram vídeos foram selecionados para a jornada de imersão.

A fim de que os participantes pudessem desenvolver suas soluções de maneira assertiva e escalável, e que sanassem problemas ligados ao ensino remoto, eles foram guiados durante o desafio através do método Google Design Sprint [Banfield, Lombardo, Wax 2015], um método que permite criar e testar um protótipo em uma semana, reduzindo significativamente o risco de falha da ideia gerada. Para isso, ao longo dos dias ocorreram três encontros diários, os check-ins, as palestras e os checkouts, que serão explicados no decorrer desta seção.

$\mathrm{O}$ encontro de check-in como teve como objetivo iniciar os trabalhos do dia, explicando quais eram as metas e como os participantes deveriam alcançá-las. As palestras estabeleciam um momento de encontro para treinamento técnico ou reflexão crítica acerca dos fundamentos e ferramentas utilizadas para realização do desafio. Para concluir as atividades no dia, o encontro de checkout era um momento para promoção de dinâmicas buscando maior integração dos participantes, bem como uma oportunidade para tirar dúvidas e reforçar sobre a dinâmica do evento.

A cerimônia de abertura ocorreu no dia dez de agosto, por meio de videoconferência. Nela, foram dadas as boas-vindas aos participantes através do pronunciamento dos representantes das instituições. As demais atividades do evento ocorreram entre os dias onze e quinze de agosto de 2020 também de forma totalmente online, por meio de videoconferências pela Internet.

O primeiro dia de desafio foi destinado à problematização do assunto em torno da educação a distância, com a enumeração de diversos problemas relacionados ao processo de aprendizagem. Para auxiliar nesse procedimento, as equipes tiveram uma palestra com conteúdo de inovação e educação, em que puderam desenvolver melhor a concepção da educação a distância de forma remota.

No segundo dia de desafio, doze de agosto, os participantes finalizaram a fase de problematização, definindo o foco final da solução, ou seja, em qual dos problemas eles atuariam, dada a inviabilidade de resolverem todos eles. Além disso, foi proposto que os participantes começassem a definição da solução e, com isso, puderam analisar diversas vertentes de propostas. Para complementar o estudo, tiveram uma palestra sobre modelagem de negócios, em que aplicaram o Quadro de Modelo de Negócios a fim de idealizar suas percepções. A ferramenta é um mapa visual que permite realizar o gerenciamento estratégico de um modelo de negócios, através da descrição da lógica de criação, entrega e captura de valor por parte de uma organização [Osterwalder \& Pigneur 2010].

O terceiro dia, treze de agosto, foi voltado para que as equipes desenvolvessem o protótipo das soluções propostas, ou seja, criassem o esboço de como seria a solução final, levando em consideração o melhor caminho para resolver os problemas do modelo desenvolvido. Para completar o dia, contaram com uma palestra em que foram 
desmistificadas diversas questões ligadas ao empreendedorismo. Neste dia, os participantes também preencheram o Value Proposition Canvas, a fim de identificarem geradores de ganho nas soluções. A ferramenta é uma estrutura para garantir que haja um ajuste entre o produto e o mercado, sendo uma visão mais detalhada entre o perfil do cliente e a proposta de valor de um negócio [Osterwalder, Pigneur, Bernarda, Smith 2014].

$\mathrm{Na}$ sexta feira, quarto dia de desafio, os participantes tiveram como objetivo realizar testes com usuários. Para isso, utilizaram o protótipo desenvolvido e realizaram uma sequência de indagações e observações com os afetados pelos problemas que eles queriam resolver. Para finalizar o dia tiveram uma palestra sobre como poderiam potencializar suas apresentações para o último dia de desafio.

No último dia do evento, os participantes tiveram que apresentar as soluções desenvolvidas durante a semana no formato de um Pitch de 3 minutos, sendo avaliados por uma banca composta por mentores nas áreas de design, tecnologia, educação e negócios. As equipes foram avaliadas quanto à aplicabilidade da solução, viabilidade de implementação, se ela era inclusiva, o nível de desenvolvimento e também pela apresentação. Cada item foi pontuado com o entendimento subjetivo de cada avaliador em uma escala de 10, sendo a nota final calculada a partir da média da pontuação de todos os quesitos de todos os avaliadores. Dos 7 grupos formados, os três que apresentaram as melhores soluções escolhidas por uma banca de avaliação foram premiados.

O primeiro colocado, denominado Grupo A, desenvolveu uma solução voltada para resolver os problemas relacionados à falta de motivação dos professores e alunos. A equipe que ocupou a segunda colocação (Grupo B) atuou na resolução dos problemas ligados à rotina, organização do tempo de estudos e às emoções negativas decorrentes da falta de planejamento. Já o grupo colocado em terceiro lugar (Grupo C) atuou no desenvolvimento de uma solução que pudesse distribuir melhor os conteúdos para os alunos e gerar uma conexão melhor entre professores e estudantes.

Além das propostas desenvolvidas pelos grupos premiados, o Grupo D apresentou como solução uma plataforma de acesso à informação, a fim de capacitar o corpo docente. O Grupo E propôs uma solução com o objetivo de alinhar cinema e os conhecimentos acadêmicos do ensino médio, criando um ambiente de ensino representativo em sala de aula. Já o Grupo $\mathrm{F}$ pensou em uma solução utilizando realidade virtual, cujo objetivo é tornar o acesso de alunos, pais e professores mais dinâmico e atrativo. O Grupo $G$ não chegou a desenvolver uma solução, tendo como justificativa a indisponibilidade de todos os membros de participarem do processo completo de ideação.

Por meio de uma pesquisa respondida espontaneamente por 21 participantes (58,3\% de todos os participantes) do evento foi possível obter os níveis de satisfação geral com as palestras, encontros diários e com o evento no geral. Na Figura 2 são apresentados os resultados obtidos quanto à avaliação dos check-ins, evento este ocorrido em todos os dias do desafio, destinado apresentar as missões diárias aos participantes e realização de dinâmicas para descontração dos mesmos. 


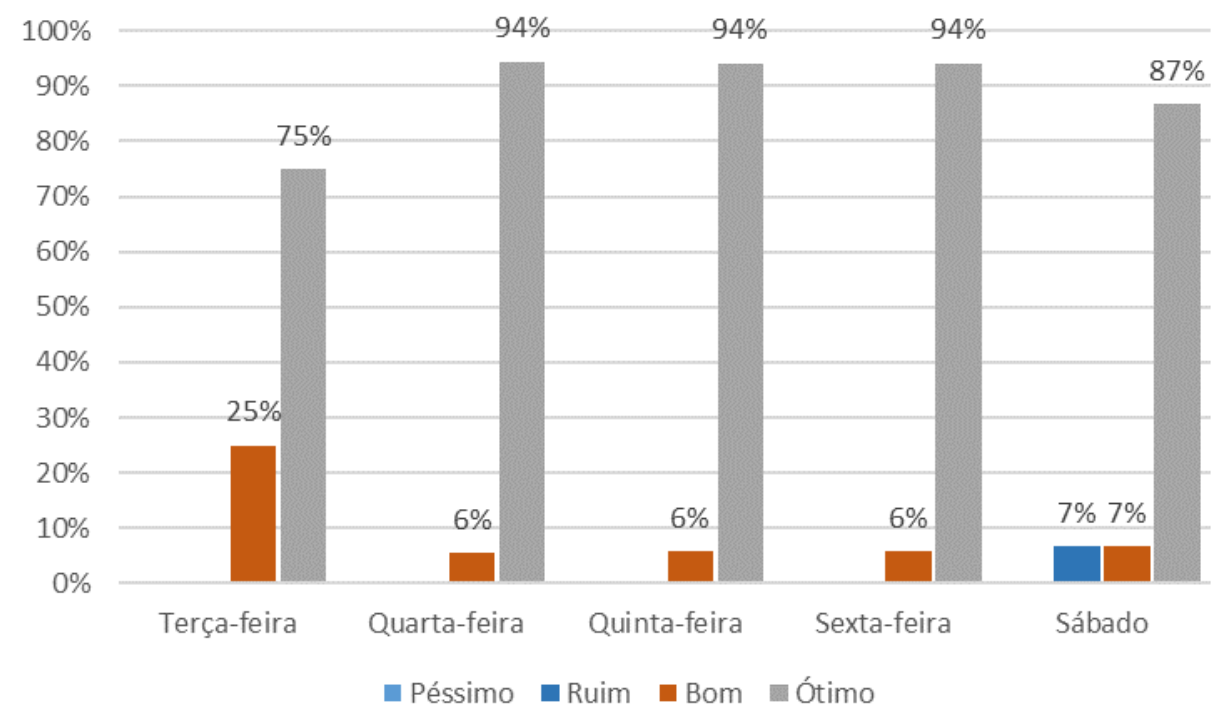

Figura 2. Avaliação dos participantes quanto ao check-in

Na Figura 3 é exibido o gráfico contendo a avaliação das quatro palestras que ocorreram ao longo do desafio. Através delas, convidados passavam aos participantes conhecimentos relacionados à temática do dia.

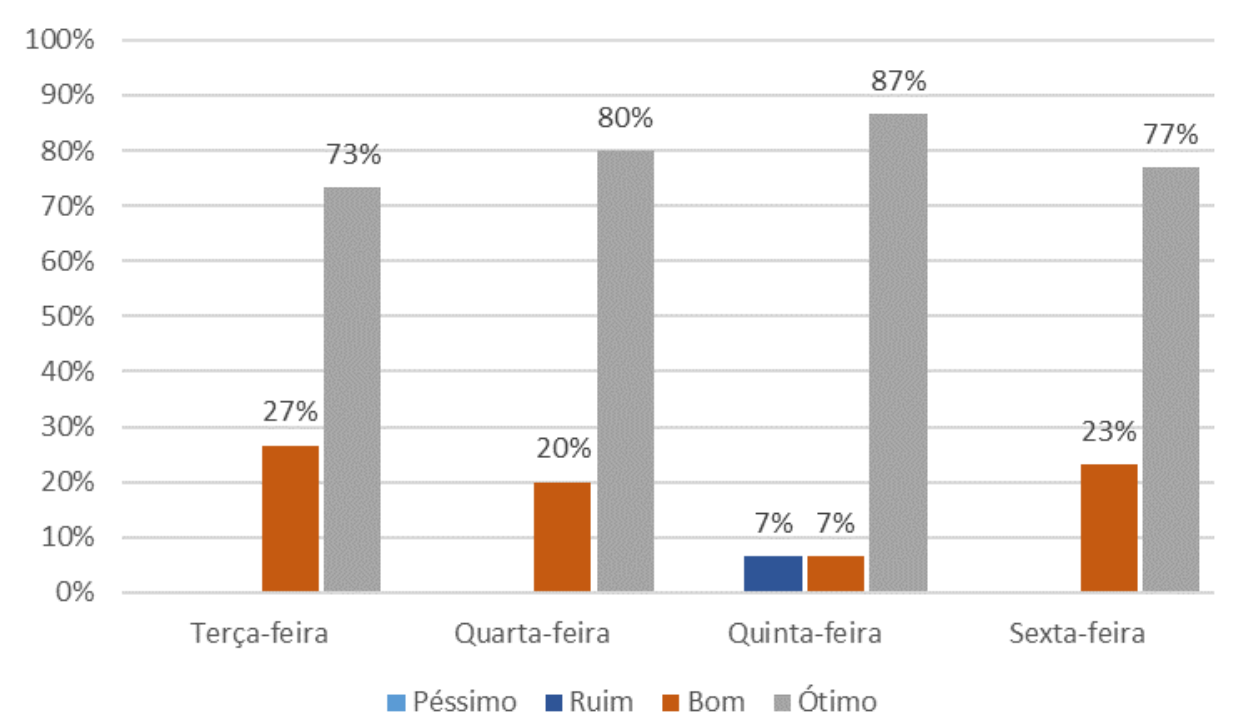

Figura 3. Avaliação dos participantes quanto às palestras

Na Figura 4 estão disponíveis os resultados da avaliação dos participantes do evento quanto aos chekouts, evento esse que ocorreu nos quatro primeiros dias do desafio com o propósito de finalizar as atividades diárias estabelecidas e promover dinâmicas com os participantes buscando a integração e reflexão sobre o tema. 


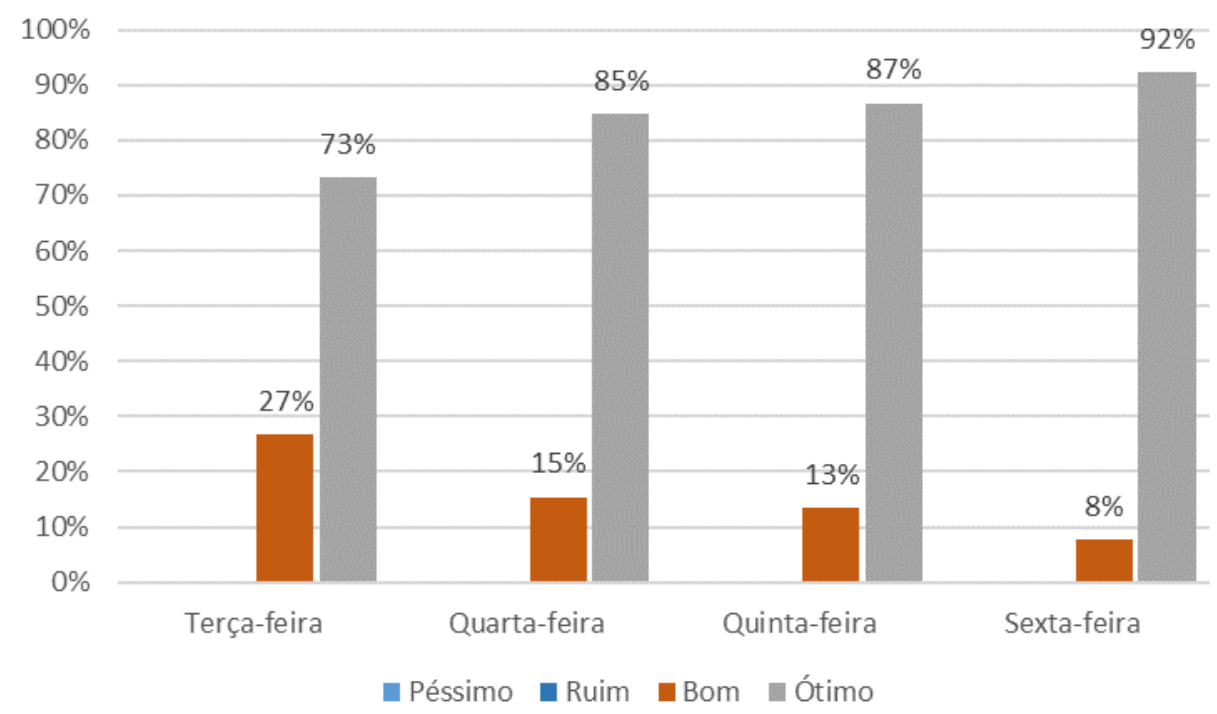

Figura 4. Avaliação dos participantes quanto ao chekout

Além das pesquisas realizadas quanto à avaliação de cada encontro, os participantes foram também questionados quanto à avaliação geral do evento. Dessa forma, $76,2 \%$ dos que responderam a pesquisa consideraram o evento 'ótimo' e $23,8 \%$ julgaram o evento como 'bom'.

Por fim, foi realizada uma pesquisa baseada em uma métrica de lealdade do cliente, o Net Promoter Score (NPS $\left.{ }^{\circledR}\right)$, que consiste em perguntar aos participantes a probabilidade de indicação para conhecidos, em uma escala de 0 a 10 , em relação à participação no evento. No modelo NPS ${ }^{\circledR}$ os participantes são classificados em três categorias, sendo que os promotores aqueles que dão nota 9 ou 10 , enquanto os detratores dão notas 1 a 6 , e os demais (notas 7 ou 8) são considerados passivos. A nota final corresponde a porcentagem de promotores menos a dos detratores. Na avaliação do evento proposto, o resultado obtido foi de $76 \%$, sendo importante ressaltar que não houve nenhum detrator.

Conforme apresentado, o evento foi realizado de forma totalmente online. Isso foi viabilizado através da utilização de plataformas de videoconferências, como forma de realizar a integração entre os participantes, mentores e organização. Todos os participantes do evento assinaram um Termo de Autorização de Uso de Imagem. A Figura 5 retrata o ambiente virtual da realização de uma das palestras.

\section{Discussão}

Considerando que a proposta principal apresentada neste artigo é um evento para promover uma competição de inovação, é importante ressaltar uma definição de inovação. O decreto $n^{\circ}$ 9.283/2018 que regulamenta o Novo Marco Legal da Ciência, Tecnologia e Inovação no Brasil (Lei $n^{0}$ 13.243/2016) define inovação como a introdução de novidade ou aperfeiçoamento no ambiente produtivo e social que resulte em novos produtos, serviços ou processos ou que compreenda a agregação de novas funcionalidades ou características a produto, serviço ou processo já existente que possa resultar em melhorias e em efetivo ganho de qualidade ou desempenho [Brasil 2016]. 


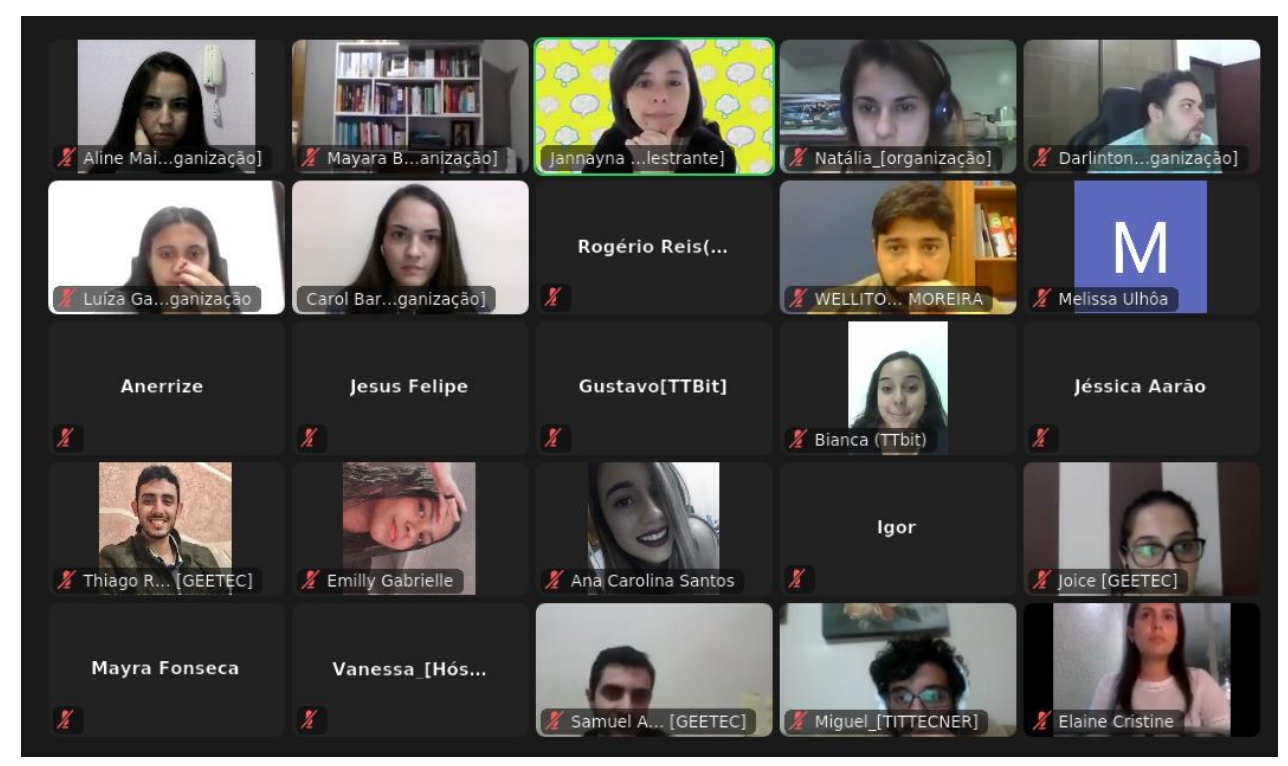

Figura 5. Captura de tela realizada durante uma das palestras

Neste sentido, observa-se que o hackathon promovido foi um estímulo à atividade de inovação na comunidade, gerando a cooperação entre diferentes públicos e organizações em prol de um objetivo em comum: criação de soluções inclusivas e escaláveis que pudessem reduzir ou eliminar alguns dos problemas enfrentados pelas redes de ensino fundamental, médio e superior.

Em relação ao contexto no qual o hackathon foi inserido, a organização tinha a expectativa de que os participantes, distribuídos entre alunos de ensino médio e superior, estivessem abertos à criatividade e a criar conexões não apenas com os integrantes de seus grupos, mas também com os demais, bem como aprimorassem os conceitos de trabalho em equipe, oportunidade de se desenvolver frente aos problemas, superação de desafios e essencialmente, aproveitassem os momentos de diversão sugeridos pelos instrutores. As avaliações obtidas e mostradas na Seção 3, bem como as soluções desenvolvidas, mostram a satisfação dos participantes diante da participação no evento e demonstram que os objetivos em relação ao comportamento dos membros selecionados foram alcançados.

Diversos setores da sociedade de beneficiam das TICs digitais e, por isso, essas ferramentas se tornam utensílios essenciais para a vida no século XXI [Correa, Seabra, Ferraz 2018]. Analisando as soluções e os artefatos computacionais propostos pelos participantes, percebe-se que a maioria dos grupos buscou solucionar os problemas do ensino remoto através da utilização de tecnologias disponíveis, como a implementação de aplicativos e plataformas web/mobile, realçando o fato de que as TIC fazem cada vez mais parte do cotidiano das pessoas, exercendo grande influência sobre elas.

Dentre todas as propostas desenvolvidas apenas um dos grupos, o Grupo F, se arriscou a propor uma solução singular às demais por meio do uso de realidade virtual $(\mathrm{RV})$. A banca avaliadora considerou a proposta inovadora e apropriada para melhorar a interação entre os envolvidos no processo de educação. Por outro lado, existem diversos desafios a serem superados para o uso da RV como recurso educacional. Um deles diz respeito ao nível de complexidade decorrente da promoção de mudanças em conteúdos projetados para suportar RV, convertendo-se em um desafio bastante técnico quanto ao 
processo de design instrucional [Cardoso, Kirner, Frango, Tori 2017]. Além disso, destaca-se também outro desafio ligado ao reuso entre dispositivos, desafio decorrente da incompatibilidade entre dispositivos.

Ao término do evento, não houve acompanhamento em relação à utilização das soluções propostas. É importante destacar que eventos deste cunho ocorrem para fomentar a promoção de iniciativas em torno de uma problemática. $\mathrm{O}$ evento promovido foi de curta duração, portanto não se deve criar expectativas de que os projetos dos participantes sejam prontos para uso, mas sim de que os desafiados possam ser estimulados e capacitados a desenvolverem soluções práticas e usuais.

No decorrer do evento foi notada a importância da utilização de ferramentas computacionais para viabilizar o hackathon. A plataforma Zoom ${ }^{\circledR}$, por exemplo, foi utilizada como meio de contato entre os envolvidos no projeto, pois ela permite a divisão dos participantes em salas, utilidade essencial para que eles pudessem desenvolver as atividades propostas. Assim como na maratona Hack for Brazil | Covid19 [Verschoore, 2020], constata-se que a cooperação em rede pode ajudar a enfrentar os desafios em eventos online, sobretudo quando diz respeito ao cenário de uma crise pandêmica. Aliado a isso, nota-se a necessidade de ter pessoas capacitadas tecnicamente que possam ser designadas para a manipulação das plataformas. Um dos contratempos ocorridos foi a dificuldade de integração entre o Zoom ${ }^{\circledR}$ e o Youtube ${ }^{\circledR}$ ao realizar a transmissão da abertura do evento. Associado à cooperação em rede percebe-se também a necessidade de apoiadores e patrocinadores que possam viabilizar o evento, tanto para que os participantes tenham recompensas pelo desenvolvimento das soluções, quanto para que os organizadores tenham pessoas a quem recorrer, caso ocorram problemas como o da integração entre plataformas.

Assim como na pesquisa "Um estudo sobre apropriação tecnológica no fomento à hospedagem alternativa em cidades de pequeno porte" [Oliveira, Viterbo, Boscarioli 2020], em que o município de pequeno porte pesquisado apresentou baixo índice de adeptos à plataforma digital AirBnB, o hackathon proposto por organizações da cidade de São João del Rei não teve como maioria participante moradores da cidade, sendo que estes representaram apenas 3 dos 36 selecionados. Esse fato revela a indispensabilidade de divulgação do evento, sobretudo dentro das instituições organizadoras, como meio de alcançar estudantes que possam contribuir.

O Hackathon das Vertentes foi um evento que contou com a contribuição de aproximadamente cem envolvidos, dentre participantes, organizadores, colaboradores de diversos segmentos da sociedade bem como patrocinadores. A quantidade de pessoas envolvidas, somada as ideias geradas demonstram que a cooperação articulada pelas universidades pode contribuir amplamente no enfrentamento de alguns dos desafios gerados pela pandemia. No Hackathon das Vertentes é notável que os grupos que se mantiveram engajados durante todo o período do evento conseguiram entregar resultados plausíveis e bem estruturados. No Hack for Brazil | Covid-19 os envolvidos destacaram o sentimento de empoderamento ao criarem soluções, o que não seria possível se atuassem de maneira isolada. Eventos deste tipo fomentam a produção coletiva, a geração de ideias inovadoras, bem como instigam organizações a promoverem iniciativas similares. 


\section{Conclusão}

Dado o atual cenário de pandemia é notável que viabilizar a educação através de novas tecnologias digitais seja um poderoso instrumento para transmitir o conhecimento. Pensando nisso, os organizadores do primeiro Hackathon das Vertentes viabilizaram um ambiente de ideação para que os participantes construíssem soluções que pudessem viabilizar a implementação dessa ferramenta, dadas as dificuldades existentes nesse processo. Os desafios da educação a distância são diversos, mas, através do hackathon foi possível contornar alguns desses obstáculos e concretizar o propósito do evento: trabalhar na construção de uma educação acessível de qualidade e para todos.

Através da metodologia baseada na proposta de Pimentel, Filippo e Santoro (2020), foi possível concluir este trabalho dando um rigor acadêmico. Nela são propostos ciclos de pesquisa, que objetivam a solução de um problema real, diante de determinado contexto, através da utilização de teorias e métodos científicos que garantam a condução da pesquisa como investigação científica.

Durante o evento proposto, os participantes puderam problematizar o assunto em torno da educação a distância, elencando todos os problemas durante o processo de aprendizagem. Através disso, eles conseguiram definir em qual dos problemas atuariam, dada a inviabilidade de resolverem todos eles. A partir da definição do problema, eles iniciaram o desenvolvimento da solução e do protótipo. Por fim, para validar suas propostas, foram realizados testes com usuários através dos protótipos desenvolvidos. No último dia puderam ser avaliados quanto à aplicabilidade da solução, viabilidade de implementação, se ela era inclusiva, o nível de desenvolvimento e também pela apresentação.

Dadas as circunstâncias do evento ficou claro para a organização que, durante o planejamento, é de fundamental importância a divulgação do evento, a detenção de apoiadores e patrocinadores que possam viabilizar o evento, bem como o acesso a plataformas de qualidade. Em trabalhos futuros pretende-se realizar não apenas questionários com os participantes, mas também entrevistas para que eles possam dar sugestões e opiniões gerais sobre o evento. Também se ressalta que a participação espontânea pode criar vieses positivos, ou negativos, e uma coleta de dados compulsória representaria com mais acuidade a percepção do grupo de participantes. Além disso, espera-se realizar questionários e entrevistas com a organização, com os mentores e com a banca avaliadora. Dessa forma será possível entender as soluções propostas e a forma como elas foram desenvolvidas sob outras perspectivas.

\section{Referências}

Banfield, R., Lombardo, C. T., Wax, T. (2015), Design Sprint: A Practical Guidebook for Building Great Digital Products, O'Reilly, $1^{\text {st }}$ edition.

Brasil. Presidência da República. Lei no 11.243, de 11 de janeiro de 2016. Brasília, 2016. Disponível em: http://www.planalto.gov.br/ccivil_03/_ato20152018/2016/lei/113243.htm Acesso em: 27/03/2021.

Brasil. Ministério da Saúde. Gabinete do Ministro. Portaria n ${ }^{\circ}$ 343, de 17 de março de 2020. Brasília, 2020. Disponível em: https://www.in.gov.br/en/web/dou/-/portaria-n343-de-17-de-marco-de-2020-248564376 Acesso em: 27/03/2021. 
Cardoso, A., Kirner, C., Frango, I., Tori, R. (2017). O Desafio de Projetar Recursos Educacionais com uso de Realidade Virtual e Aumentada. In: Anais do WORKSHOP DE DESAFIOS DA COMPUTAÇÃO APLICADA À EDUCAÇÃO (DESAFIE!), 6., 2017, São Paulo. Anais [...]. Porto Alegre: Sociedade Brasileira de Computação, 2017. DOI: https://doi.org/10.5753/desafie.2017.3109

Correa, A.C.G., Seabra, R.D., Ferraz, D.P.A. (2018). Desenvolvimento de uma Plataforma Digital com Ênfase em Tecnologia, Educação e Diversidade. Revista de Sistemas e Computação, Salvador, v. 8, n. 2, p. 213-233, jul./dez. 2018.

Oliveira, N. Viterbo, J., Boscarioli, C. (2020) Um estudo sobre apropriação tecnológica no fomento à hospedagem alternativa em cidades de pequeno porte. In Anais do I Workshop sobre as Implicações da Computação na Sociedade, June 30, 2020, Cuiabá, Brasil. SBC, Porto Alegre, Brasil, 122-129.

Osterwalder, A., Pigneur Y. (2010), Business Model Generation: A Handbook for Visionaries, Game Changers, and Challengers, John Wiley \& Sons.

Osterwalder, A., Pigneur Y., Bernarda, G., Smith, A. (2014), Value proposition design: How to create products and services customers want, John Wiley \& Sons.

Pimentel, M., Carvalho, F.S.P. (2020), Princípios da Educação Online: para sua aula não ficar massiva nem maçante! In SBC Horizontes, maio 2020. ISSN 2175-9235. Disponível em: $\quad<$ http://horizontes.sbc.org.br/index.php/2020/05/23/principioseducacao-online>. Acesso em: 24 de Março de 2021.

Pimentel, M., Filippo, D., Santoro, F. M. (2020) Design Science Research: fazendo pesquisas científicas rigorosas atreladas ao desenvolvimento de artefatos computacionais projetados para a educação. In: JAQUES, Patrícia Augustin; PIMENTEL, Mariano; SIQUEIRA; Sean; BITTENCOURT, Ig. (Org.) Metodologia de Pesquisa Científica em Informática na Educação: Concepção de Pesquisa. Porto Alegre: SBC, 2020. (Série Metodologia de Pesquisa em Informática na Educação, v. 1) Disponível em: $<$ https://metodologia.ceie-br.org/livro-1/>.

Verschoore, J. R. (2020). A COORDENAÇÃO DE ESFORÇOS COLETIVOS PARA ENFRENTAR A PANDEMIA DO NOVO CORONAVÍRUS: UM ESTUDO DE CASO SOBRE O HACKATHON HACK FOR BRAZIL | COVID-19. REAd. Revista Eletrônica de Administração (Porto Alegre), 26(2), 238-264. Epub September 04, 2020. https://doi.org/10.1590/1413-2311.283.103388

World Bank (2020), The COVID-19 Pandemic: Shocks to Education and Policy Responses, World Bank, Washington, DC. DOI: https://doi.org/10.1596/33696 